\title{
A 5-gene classifier from the carcinoma-associated fibroblast transcriptomic profile and clinical outcome in colorectal cancer
}

\author{
Mireia Berdiel-Acer ${ }^{1}$, Antoni Berenguer ${ }^{2}$, Rebeca Sanz-Pamplona ${ }^{2}$, Daniel \\ Cuadras $^{2}$, Xavier Sanjuan ${ }^{3}$, Maria José Paules ${ }^{3}$, Cristina Santos ${ }^{4}$, Ramon Salazar ${ }^{4}$, \\ Victor Moreno ${ }^{2}$, Gabriel Capella ${ }^{5}$, Alberto Villanueva ${ }^{1}$, David G. Molleví ${ }^{1}$ \\ 1 Translational Research Laboratory, Catalan Institute of Oncology, IDIBELL, L'Hospitalet de Llobregat, Catalonia, Spain \\ 2 Biomarkers and Susceptibility Unit, Cancer Prevention and Monitoring Programme, Catalan Institute of Oncology, IDIBELL, \\ L'Hospitalet de Llobregat, Catalonia, Spain \\ 3 Pathology Department, Hospital Universitari de Bellvitge, IDIBELL, L'Hospitalet de Llobregat, Catalonia, Spain \\ ${ }^{4}$ Medical Oncology Department, Catalan Institute of Oncology, IDIBELL, L'Hospitalet de Llobregat, Catalonia, Spain \\ ${ }^{5}$ Hereditary Colorectal Cancer Programme, Catalan Institute of Oncology, IDIBELL, L'Hospitalet de Llobregat, Catalonia, Spain \\ Correspondence to \\ Dr. David G. Mollevi, e-mail: dgmollevi@iconcologia.net \\ Keywords: colorectal, microenvironment, carcinoma-associated fibroblast, prognosis, genetic classifier. \\ Received: May 19, $2014 \quad$ Accepted: July 14, $2014 \quad$ Published: July 23, 2014
}

\section{ABSTRACT}

Based on 108 differentially expressed genes between carcinoma-associated fibroblasts (CAFs) and paired normal colonic fibroblasts we recently reported, a 5-gene classifier for relapse prediction in Stage II/III colorectal cancer (CRC) was developed. Its predictive value was validated in datasets GSE17538, GSE33113 and GSE14095. An additional validation was performed in a metacohort $(n=317)$ and 142 CRC patients by means of RT-PCR. The 5-gene classifier was significantly associated with increased relapse risk and death from CRC across all validation series of Stage II/III patients used. Multivariate Cox regression analyses confirmed the independent prognostic value of the stromal classifier $(H R=2.67 ; P=0.002)$. Posttest probabilities provided evidence of the suitability of the 5-gene classifier in clinical practice, identifying a subgroup of Stage-II patients who were at high risk of relapse. Moreover, the a priory worst prognosis mesenchymal subtype of tumours can be stratified according to the physiological status of their carcinoma-associated fibroblasts. In conclusion the CAFs-derived 5-gene classifier provides more accurate information about outcome than conventional clinicopathological criteria and it could be useful to take clinical decisions, especially in Stage II. Additionally, the classifier put into relevance the CAF's intratumoral heterogeneity and might contribute to find relevant targets for depleting adequate CAFS subtypes.

\section{INTRODUCTION}

Colorectal cancer (CRC) is one of the most common cancer types in men and women worldwide, with more than one million new cases recorded annually [1]. The difference in prognosis between early and late stages can vary from a five-year survival rate of $93 \%$ at Stage-I, to $8 \%$ at Stage-IV [2]. For Stage-III patients, post-surgical adjuvant chemotherapy is the standard of care [3]. Although most Stage-II patients are cured by surgery alone, a proportion of them are at high risk of relapse, as determined by clinical and pathological evaluation (advanced $\mathrm{T}$ stage, few examined lymph nodes, tumor perforation and low tumor differentiation) and are candidates for adjuvant chemotherapeutic treatment [4]. However, some patients whose clinical factors suggest that they do not have a higher risk of relapse based on clinical factors still relapse, while, on the other hand, approximately $40 \%$ of patients with Stage-III CRC enrolled in surgery-only groups did not recur in five years even without adjuvant treatment [5]. These facts demonstrate that the traditional staging system is not sufficient to identify those patients with Stage-II CRC who carry a high risk of poor outcomes, and this may lead 
to potential under- or over-treatment in many situations. Identification of new biomarkers to improve prediction of high-risk patients with Stage-II CRC and consequently improved individualized cancer care are needed [6].

Many studies have used gene expression profiling to predict the risk of poor outcome in breast [7], lung [8, 9] and prostate [10] cancers, and many other tumor types. In CRC, several studies have developed gene-expression prognostic signatures to classify patients according to their relapse risk [11]. The Oncotype-DX test [12] and Coloprint $[13,14]$ are now available for Stage-II CRC patients. More recently, an effort to molecularly characterize colorectal cancer has been made $[15,16]$, emphasizing the high degree of inter-tumor heterogeneity of this entity $[17,18]$. Adding further to its complexity, it features intra-tumor heterogeneity, whereby the balance between tumor and stroma and their respective transcriptional status play a crucial role. In that sense, the response of fibroblasts to TGF $\beta$ is a mainstream factor for the development of more aggressive tumor cells [19].

Given the importance of stromal elements in modulating and driving cancer progression, it is crucial to determine the contribution of the stroma and to understand the consequences of changes in this tissue compartment. It has been suggested that changes in the tumor microenvironment may benefit the tumor by enhancing proliferation, inducing a more invasive malignant phenotype, and increasing chemoresistance $[20,21]$. These stromal changes consist of activation of resident fibroblasts in carcinoma-associated fibroblasts (CAFs), increased matrix deposition, new blood vessel formation and immune cell infiltration. CAFs are the main constituents of tumor stroma and they exist in close proximity to the cancer epithelium. In a previous study (Molecular Oncology 10.1016/j.molonc.2014.04.006), we defined a signature of 108 genes that are deregulated in CAFs from primary tumors relative to normal colonic fibroblasts (NCFs) from adjacent mucosa in CRC patients. The aim of the present work is the development of a stromal genetic classifier from the 108 deregulated genes previously reported by our group. Thus, we defined a 5-gene stromal classifier that could predict the risk of relapse in different independent datasets of whole-tumor samples. To extend this work, we wanted to assess the predictive power of these genes, analyzing expression levels by means of quantitative real-time PCR in a set of 142 fresh samples in order to exploit its clinical value in a more amenable and reproducible technique.

\section{RESULTS}

\section{Identification of the prognostic stromal classifier}

In our previous work (Molecular Oncology 10.1016/j.molonc.2014.04.006), we obtained a list of
108 deregulated genes (DEG) between NCFs and paired CAFs, fitting the following criteria:

- having at least one associated gene;

- mean log RMA expression $>4$, to exclude background and low-abundance probes,

- standard deviation log RMA expression $>0.1$, to exclude low-variability probes;

- q-value $<0.05$;

- $>2$-fold change for overexpressed genes and $<0.5$-fold change for underexpressed genes.

We previously reported the functional relationship of those genes in CAFs biology and the processes in which they are involved (Molecular Oncology 10.1016/j. molonc.2014.04.006).

The aim here is to define a CAFs-derived classifier from the 108 DEG. The entire process of development and validation of the classifier is illustrated in Figure 1. The selected genes were CCL11 (downregulated in CAFs versus paired NCF; protective gene) and PDLIM3, AMIGO2, SLC7A2, ULBP2 (overexpressed in CAFs versus paired NCF).

In the training set, the classifier was not statistically associated with stage $(\mathrm{P}=0.629)$, patient age $(\mathrm{P}=0.584)$, gender $(\mathrm{P}=0.808)$, tumor location $(\mathrm{P}=0.144)$ or adjuvant treatment $(\mathrm{P}=0.469)$.

The expression of classifier genes is mainly fibroblast-specific (Supplementary Figure 1A). To demonstrate that these five genes have prognostic value if the stroma is present in a given sample, we checked our signature in two independent datasets of LCM (Laser Capture Microscope) epithelial cell-enriched samples. As shown in Supplementary Figure 1B and C, the classifier has no predictive power over recurrence in GSE18105 (AUC=0.50) and GSE21510 (AUC=0.53), for which both datasets were enriched in epithelial cells. Additionally, although ULBP2 can be also expressed in epithelial cells, the contribution of this gene to prognosis is negligible, at least in the two datasets of laser capture enriched samples checked (Supplementary figure 1D and E). We also excluded a possible contribution of cells to the epithelial to mesenchymal transition (EMT) process that would account for the expression of classifier genes (Supplementary Figure 1F-G). Considering these results, we concluded that the epithelial cells did not interfere with EMT masking the performance of the classifier.

\section{The 5-gene classifier identifies patients with colorectal cancer with poor outcome in three independent in silico datasets}

Regarding the cut off obtained in the training dataset (GSE14333) to segregate patients according to relapse risk $\left(3^{\text {rd }}\right.$ tertile, cut off classifier score $=1.1328$; Figure $\left.2 \mathrm{~A}\right)$, we then chose datasets of whole tumor samples as validation series, thereby ensuring a certain minimum 


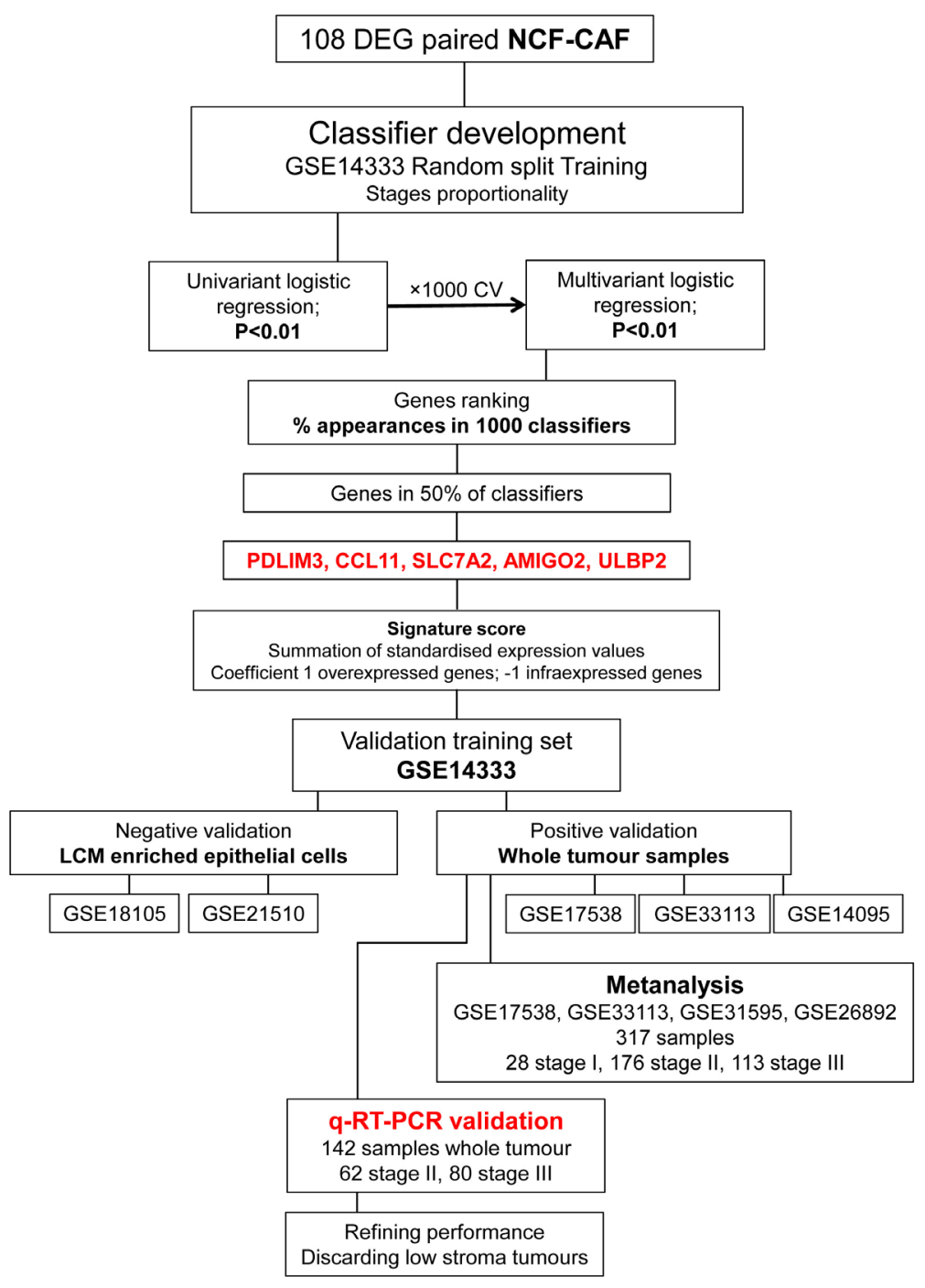

Figure 1: Recurrence classifier development. The 5-gene classifier is derived from a 108-gene signature of differentially expressed genes (DEGs) between carcinoma-associated fibroblasts (CAFs) and paired normal colonic fibroblasts (NCFs) (Molecular Oncology 10.1016/j.molonc.2014.04.006). To develop a prognostic classifier we obtained RMA expression values of the 108 DEGs from 135 Stage II and III cases (GSE14333; excluding non-recurrent patients with a follow up of $<3$ years; 87 without 48 with recurrence), we used the random resampling procedure to maintain stage proportionality, and divided the initial 135 cases into training and test sets $(66 \%$ and $33 \%$ of cases, respectively). The latter was not involved in gene selection in order to avoid model overfitting. Transcript cluster IDs corresponding to the 108 DEGs (Affymetrix GeneChip Human Gene 1.0 ST Array) between NCF and CAF were mapped to probe set IDs in GSE14333 (Affymetrix Human Genome U133A Plus 2.0 Array). We did a univariate binary logistic regression for each gene, using recurrence as the dependent variable. We chose genes for which $\mathrm{p}<0.01$ to model an L1 penalized GLMNET multivariate logistic regression in the training set. We then ran the model with the validation dataset. We repeated this process 1000 times, obtaining 1000 classifiers. We recorded all 1000 intermediate signatures, considering only genes and discarding $\beta$ regression coefficients in order to apply the same biological relevance (same weight) to all genes. We ranked the percentage of times each candidate gene appeared in the signatures, selecting those present in $>50 \%$ of signatures for the final classifier. The selected genes were PDLIM3, AMIGO2, SLC7A2, ULBP2 and CCL11. A recurrence score for each sample was computed as the sum of the z-scores of each gene. No gene level parameters were estimated in order to assign the same biological relevance to all five genes (as detailed above), and coefficients were established as 1 for overexpressed genes in CAF vs. NCF (PDLIM3, SLC7A2, ULBP2 and AMIGO2; risk genes) and -1 for underexpressed genes in CAF vs. NCF (CCL11, protective gene).

The genes were firstly negatively validated in two datasets of epithelial cell-enriched samples to test their stromal specificity. Moreover, the classifier was validated in silico in independent datasets of whole-tumor samples and in an independent cohort of 142 cases of Stage II/III colorectal cancers by quantitative real-time PCR.

To conduct the Kaplan-Meier analysis, patients were segregated in two risk groups using the cut off obtained in the training dataset (cut off classifier score $=1.1328$; third tertile; $>1.1328$ high-risk of relapse; $<1.1328$, low-risk of relapse). The third tertile is approximately the relapse prevalence in colorectal cancer (approximately $33.3 \%$ ). 
A

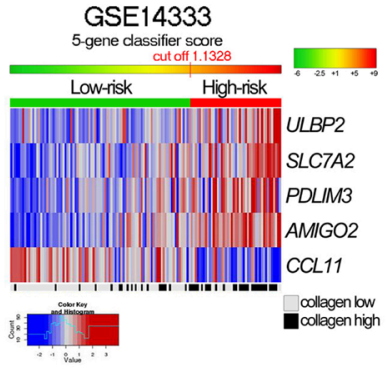

D

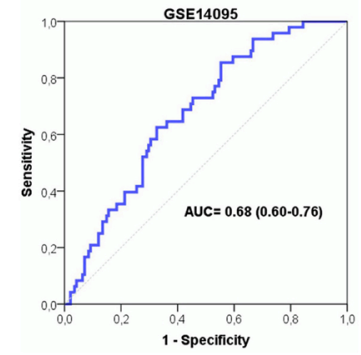

B

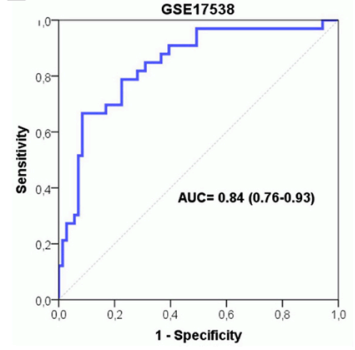

E

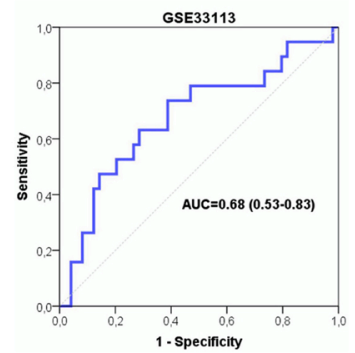

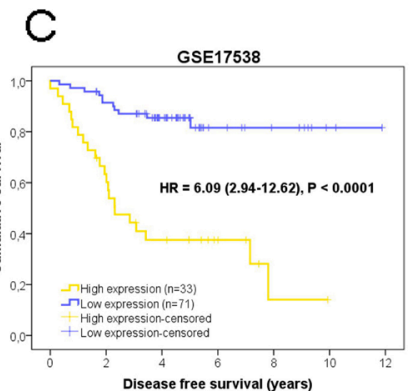

F

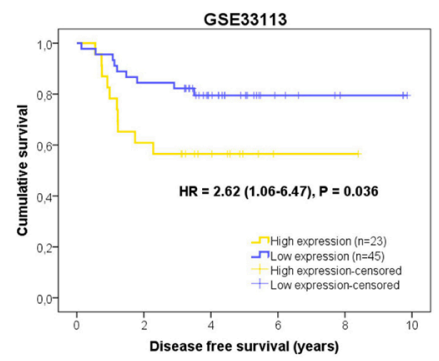

G $\mathrm{H} \quad$ I

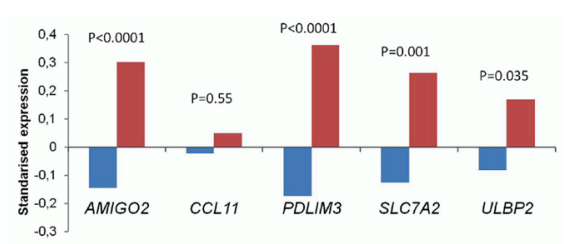

mon-recurrent $(\mathrm{n}=214)$

m recurrent $(\mathrm{n}=103)$
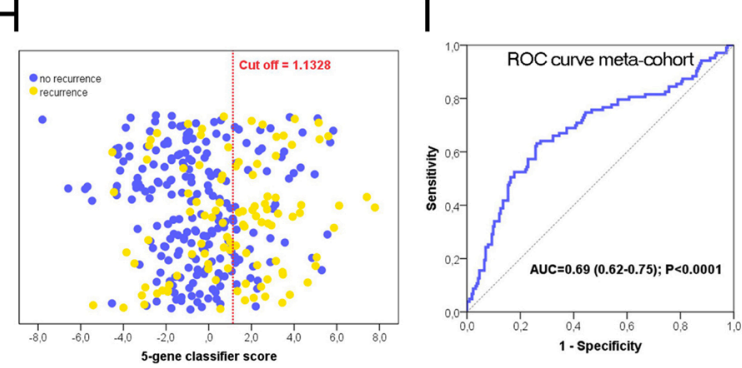

J

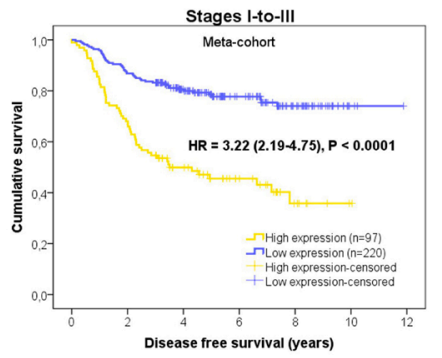

K

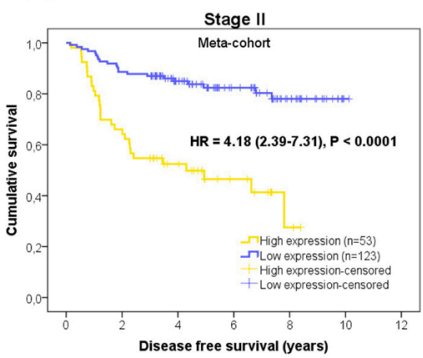

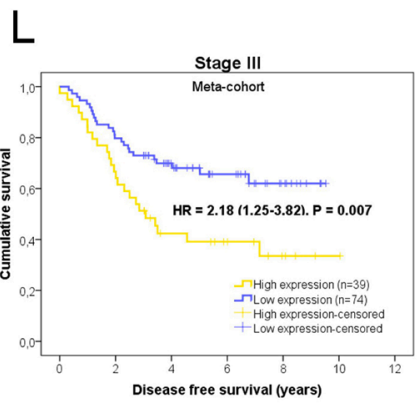

Figure 2: (A) Heatmap of expression values of the 5 genes of the classifier in patients of the training dataset. The cut off 1.1328 (the $3^{\text {rd }}$ tertile of the score) segregates patients in two groups of risk. Performance of the 5-gene classifier in the validation dataset GSE17538, (B) (ROC curve), and (C) Kaplan-Meier analysis of disease free survival. High expression patients (yellow) have a hazard ratio 6.08 times higher to relapse than low expression patients (blue). (D) To confirm the prognostic stromal classifier we used another independent dataset (GSE14095), displaying a $\mathrm{AUC}=0.68$. No survival time information was available for this dataset in order to display Kaplan-Meier curves.

An additional validation (E) was performed with GSE33113 (Stage II colorectal cancer patients). (F) High expression patients (yellow) have a hazard ratio 2.62 times higher to relapse than low expression patients (blue), $\mathrm{P}=0.036$. In this dataset, for a unit increase in the classifier score, the risk of relapse increases by $1.206(95 \% \mathrm{CI}=1.036-1.403 ; \mathrm{P}=0.016)$.

(G) Standardized expression values of the five genes in the metanalysis cohort ( $\mathrm{n}=317$ ), including GSE17538, GSE33133, GSE31595 and GSE26892. Four genes (AMIGO2, ULBP2, PDLIM3 and SLC7A2) are significantly higher in recurrent tumors compared to nonrecurrent tumors (statistical significance assessed by the Student's t-test).

(H) Scatter plot of the 317 patients of the meta-cohort according to the 5-gene classifier score (yellow dots recurrent patients, blue dots non-recurrent patients The red dotted line is the cut off obtained in the training dataset to categorize patients according to risk of relapse. The receiver operating characteristic curve describes the performance of the 5-gene classifier in this large cohort (I).

(J to L) Kaplan-Meier curves in the meta-cohort. 
stroma percentage (approximately $>20-25 \%$, as detailed at GEO). Consequently, we ascertained the performance of the 5-gene classifier in GSE17538 (Figure 2B and C; $\mathrm{AUC}=0.84 ; \mathrm{HR}=6.09 ; \mathrm{P}<0.0001$ ), GSE14095 (AUC=0.68; Figure 2D) and GSE33113 (Stage II, Figure 2E and F; $\mathrm{AUC}=0.68, \mathrm{HR}=2.62, \mathrm{P}=0.036$ ).

Survival information data were not available for the GSE14095 dataset (recurrence status only).

\section{In silico validation: meta-cohort}

We merged the previous GSE17538 and GSE33113 validation datasets, and added two more datasets, GSE31595 and GSE26892, to create a metacohort of 317 patients (28 Stage-I, 176 Stage-II and 113 Stage-III). Since the score was calculated using Z-scores for each gene and dataset before merging, the impact of the centre/hospital bias was negligible. The association of each single gene of the classifier with the recurrence status is illustrated in Figure $2 \mathrm{G}$ and the performance of the classifier in predicting recurrence is depicted in Figures $2 \mathrm{H}$ and I. Therefore, according to the cut off (1.1328), 30.6\% and $69.4 \%$ of patients with the higher 5 -gene signature score were identified respectively as high- and low-risk. Low-risk patients had a 5-year DFS rate of 73\%, whereas the rate in high-risk patients was only $36 \%$ (Figure $2 \mathrm{~J}$ ). Using the 5-gene signature score as a continuous variable, the HR increased by $1.236(95 \% \mathrm{CI}=1.15-1.33)$ per unit increase in the SD of expression. Stratifying by disease stage (Figures 2K and L) revealed 5-year DFS rates of $33 \%$ in high-risk Stage-II patients, $77 \%$ in low-risk patients $(\mathrm{HR}=4.18,95 \% \mathrm{CI}=2.39-7.31, \mathrm{P}<0.0001)$ and $\mathrm{HR}=2.18$ (95\% CI $=1.25-3.82, \mathrm{P}=0.007)$ for high-risk Stage-III patients (5-year DFS rate of 33\% versus 59\% of low-risk).

To assess the potential utility of the 5 -gene classifier in clinical practice we evaluated the post-test recurrence probabilities and compared them with the a priori expected prevalence (Table 2).

For this metacohort, a detailed comparison of the 5 -gene classifier with clinical factors was not possible because limited information across all GEO datasets further than age, gender and stage. Other variables such as tumor grade was only available for GSE17538 and adjuvant treatment, isolated nodes, lymphatic invasion were not available.

\section{PCR validation in an independent cohort of 142 patients}

We aimed to translate the 5-gene signature score obtained by means of microarray technology to a technique that was more convenient and less subject to bias, such as real-time PCR. For this purpose we used a cohort of 142 well annotated Stage II/III colorectal cancer patients from our institution. Patient characteristics are summarized in Table 1.

Table 1. Patient demografics and clinical characteristics for the training set, in silico validation metacohort and real timeNAPCR validation set.

\begin{tabular}{|l|l|l|l|}
\multicolumn{2}{l}{ Training setGSE14333 } & $\begin{array}{l}\text { Validation in silico } \\
\text { metacohort }\end{array}$ \\
\hline Cohort size & 135 & 317 & 142 \\
\hline Gender & & & \\
\hline Male & $76(56.3)$ & $104(51.2)^{*}$ & $80(56.3)$ \\
\hline Female & $59(43.7)$ & $99(48.8)^{*}$ & $62(43.7)$ \\
\hline Mean age & 64.38 & $66.91^{*}$ & 66.71 \\
\hline Stage & & & \\
\hline Stage I & NA & $28(8.8)$ & NA \\
\hline Stage II & $64(47.4)$ & $176(55.5)$ & $62(43.7)$ \\
\hline Stage III & $71(52.6)$ & $113(35.6)$ & $80(56.3)$ \\
\hline Location & & & \\
\hline Colon & $118(87.4)$ & NA & $91(64.1)$ \\
\hline Rectum & $17(12.6)$ & NA & $51(35.9)$ \\
\hline Grade & & & \\
\hline Low & NA & NA & $128(90.1)$ \\
\hline High & NA & NA & $14(9.9)$ \\
\hline
\end{tabular}

(Continued) 
Table 1. Patient demografics and clinical characteristics for the training set, in silico validation metacohort and real timeNAPCR validation set. (Continued)

\begin{tabular}{|l|l|l|l|}
\hline \multicolumn{2}{l}{ Training setGSE14333 } & Validation in silico \\
metacohort & & \\
\hline Isolated nodules & & & Validation PCR dataset \\
\hline$>14$ & NA & NA & $96(67.6)$ \\
\hline$<14$ & NA & NA & $46(32.4)$ \\
\hline Adjuvant chemotherapy & & & \\
\hline$y e s$ & $69(51.1)$ & NA & $74(52.1)$ \\
\hline$n o$ & $66(48.9)$ & NA & $68(47.9)$ \\
\hline Recurrence & & & \\
\hline$y e s$ & $48(35.6)$ & $103(32.5)$ & $43(30.3)$ \\
\hline$n o$ & $87(64.4)$ & $214(67.5)$ & $99(69.7)$ \\
\hline Kras status & & & \\
\hline$w t$ & NA & NA & $73(51.4)$ \\
\hline$m u t$ & NA & NA & $47(33.1)$ \\
\hline NA & NA & NA & $22(15.5$ \\
\hline MSI status & & & \\
\hline high & NA & NA & $19(13.4)$ \\
\hline MSS & NA & NA & $100(70.4)$ \\
\hline NA & NA & NA & $23(16.2)$ \\
\hline
\end{tabular}

Abbreviations: NA not available or not reported by authors to GEO.

*Available only for 203 patients. \% are reported in brackets. Training and validation datasets used were relatively similar in relation to gender, age and recurrence status. Additionally, PCR validation cohort was very similar to the training dataset (GSE14333), with respect to the number of patients, stage distribution and percentage of patients treated in adjuvancy. There were some differences involving the distribution of tumour location in the colon and rectum. A previous report by our group demonstrated that there are no differences at the molecular level between tumours of the colon and rectum [ (SanzNAPamplona R, Cordero D, Berenguer A, et al. Gene expression differences between colon and rectum tumors. Clin Cancer Res;17:7303NA12.).

As depicted in Figure 3A, recurrent samples clearly have higher classifier scores than non-recurrent samples $(\mathrm{P}=0.007)$. In this cohort, using the cut off obtained in the training dataset, $31 \%$ of patients were considered high-risk (44 high-expression patients, Figure 3B, $\mathrm{HR}=3.14$ ) whereas $69 \%$ were classified as low-risk (98 patients; $48 \%$ Stage-II and 52\% Stage-III). Fifteen of 62 Stage-II patients were identified as high-risk according to the 5-gene classifier, only two of them being pT4. Low-risk patients had a five-year DFS rate of $80 \%$, while that of high-risk patients was only $45 \%$. Considering the stages separately, Stage-II low- and high-risk patients had five-year DFS rates of $89 \%$ and $52 \%$, respectively (Figure 3C). In Stage-III, the five-year DFS rates were $71 \%$ and $41 \%$ for low- and high-risk patients, respectively (Figure 3D). For DSS, the five-year life expectancy was clearly better for low-risk patients $(84 \%$ versus $54 \%$,
$\mathrm{HR}=3.96$, Figure $3 \mathrm{~F}$ ). High-grade tumors were more often classified as high-risk $(\mathrm{P}<0.0001)$ although the outcome may be biased by the high proportion of low-grade tumors (90.1\%). High-risk has a statistical association with recurrence, time to recurrence and time to cancer-specific death (Supplementary table 1).

In the univariate analysis the 5-gene classifier was the strongest predictor of DFS (HR $=3.14,95 \% \mathrm{CI}=1.72$ 5.72, $\mathrm{P}<0.0001$; Table 3 ). Using the 5-gene signature score as a continuous variable, the HR increased by 1.191 (95\% $\mathrm{CI}=1.05-1.35, \mathrm{P}=0.005)$ per unit increase in the $\mathrm{SD}$ of expression. Stage-III, high grade and lymphatic invasion were also associated with poor prognosis in univariate analyses of this cohort. These variables were included in the multivariate analysis (Table 3), in which the 5-gene classifier proved to be the only independent predictor of recurrence $(\mathrm{HR}=2.67,95 \% \mathrm{CI}=1.42-5, \mathrm{P}=0.002)$. 
A

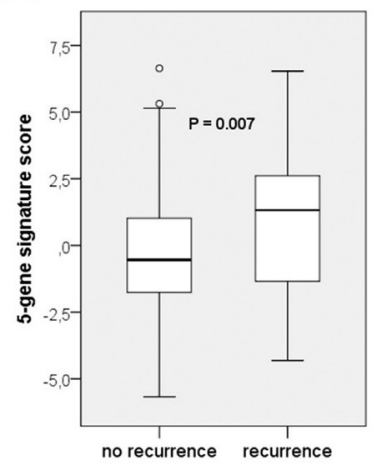

D

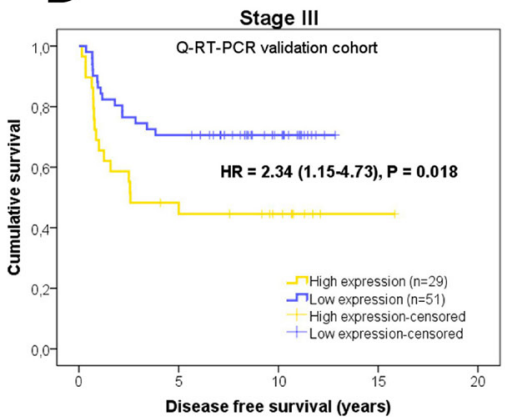

G

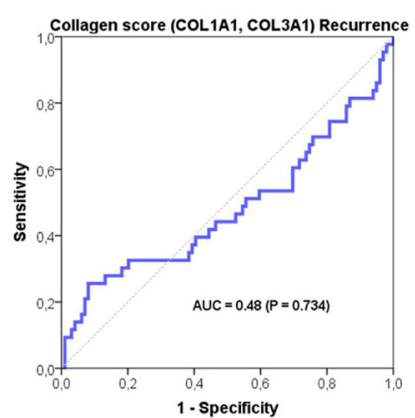

B

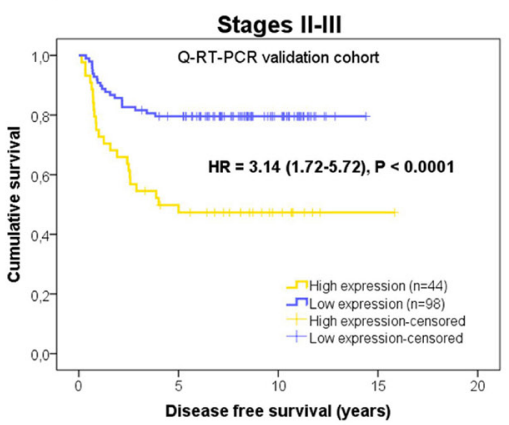

$E$

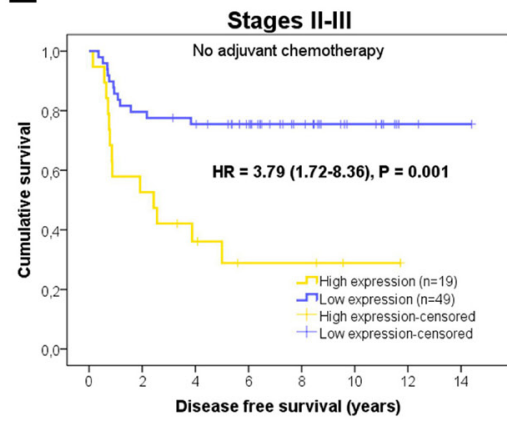

$\mathrm{H}$

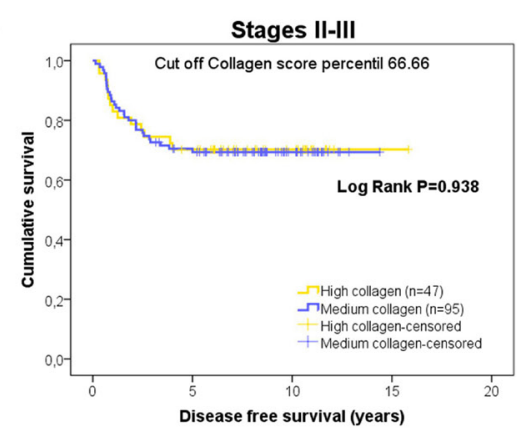

$J$

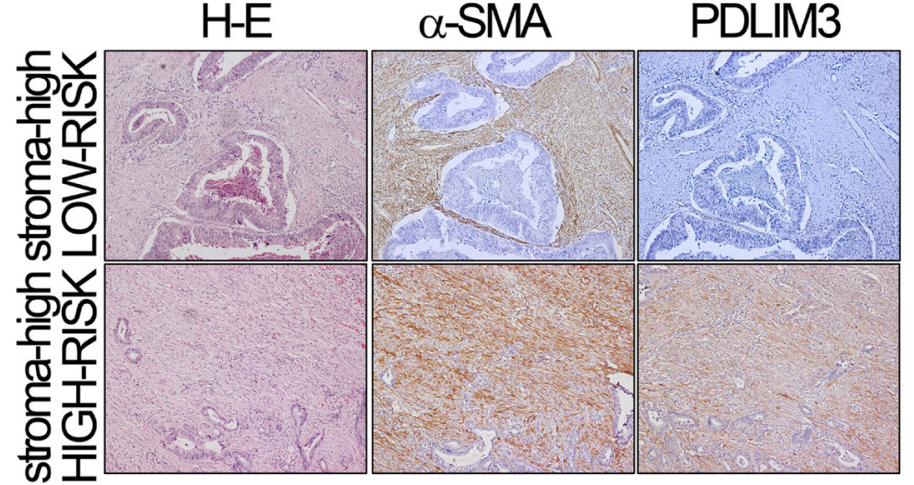

C

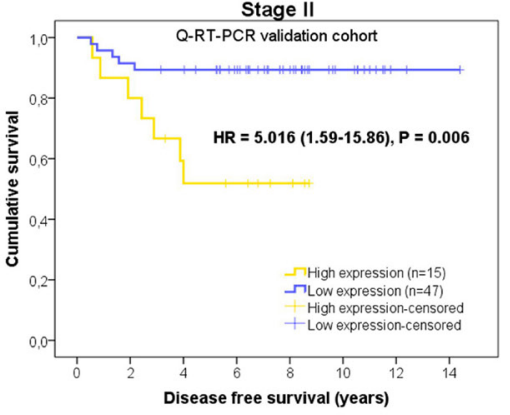

F

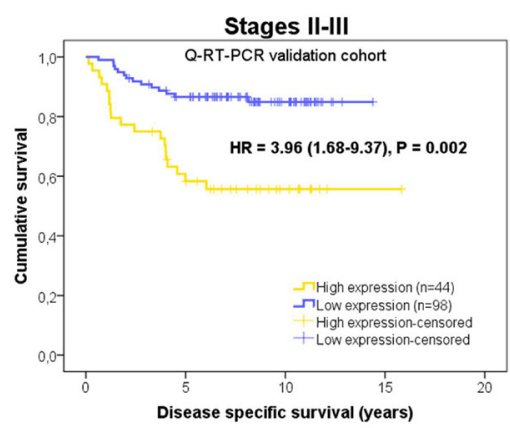

I

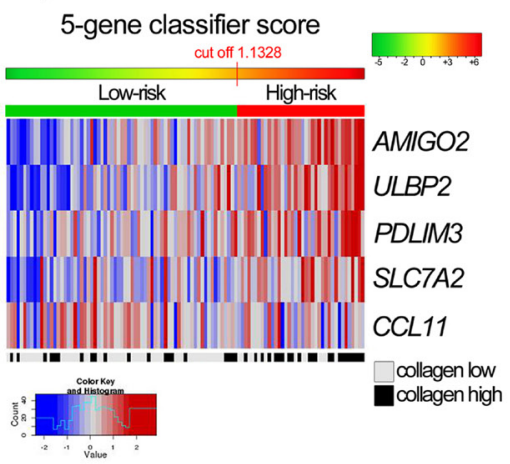

K

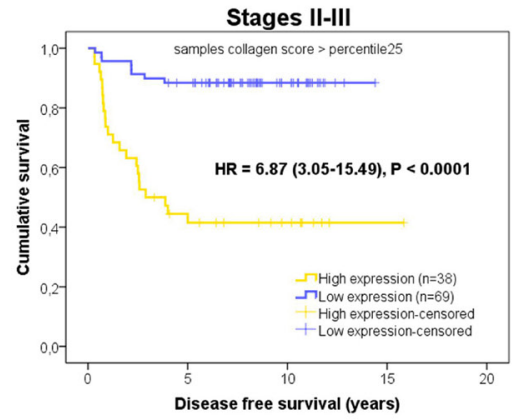

Figure 3: Prognostic information in the PCR independent validation. (A) Mean values of the 5-gene signature score according to patient recurrence in the PCR cohort of 142 samples (43 recurrent and 99 non-recurrent); t-test, $\mathrm{P}=0.007$.

(B-D) Kaplan-Meier plots for disease-free survival in all stages and Stage II or Stage III alone.

Considering only the 68 patients who did not receive adjuvant chemotherapy, the 5-gene classifier is associated with recurrence $(\mathrm{HR}=3.79,95 \% \mathrm{CI}=1.72-8.36, \mathrm{P}=0.001$; Figure $3 \mathrm{E})$.

(Continued) 
(F) Kaplan-Meier plots for disease-specific survival in all stages.

(G) Receiver operating characteristic curve describing the absence of predictive power for the recurrence of the collagen score.

(H) Using the $3^{\text {rd }}$ tertile of the collagen score as a cut off, Kaplan-Meier survival plot shows that the collagen score provides no prognostic information in terms of disease-free survival in the PCR cohort. Thus, tumors with high collagen expression have the same outcome than low collagen tumors. The collagen score does not provide prognostic information. Higher collagen values are not associated with a worse outcome.

(I) Heatmap showing individual genes included in the classifier on the basis of their expression in the PCR cohort. The cut-off value obtained from the training dataset is represented by the change from green to red in the horizontal bar over the heatmap, which defines the two risk groups. The light grey and black boxes below the heatmap depict the samples identified as low or high collagen according to the collagen score (defined as the average expression of COL1A1 and COL $3 \mathrm{Al}$ ).

Our results suggest that the prognostic value is determined by the physiological status of the CAFs rather than their quantity. In these photomicrographs (J) we illustrate two colorectal tumors, both considered as "high stroma" because of the large quantity of desmoplasia (H-E staining), strong positivity for alpha smooth muscle actin ( $\alpha$-SMA), but reflecting a distinct transcriptomic status with respect to PDLIM3 staining. In the top right panel, CAFs display no staining for PDLIM3, one of the five genes of the classifier, and in addition, the tumor is classified as low-risk, according to the mRNA expression values of the five genes. Conversely, in the bottom right panel, CAFs display intense PDLIM3 staining, and the tumor is considered high-risk when considering the expression of all five genes.

(K) Our hypothesis is that the performance of the 5-gene classifier increases if considering specimens with a minimum number of fibroblasts. Samples with very low levels of fibroblasts will have a very poor representation of mRNA transcripts from fibroblast origin and will therefore be misclassified. As a proof of concept, we selected samples with a collagen score above the $25^{\text {th }}$ percentile, excluding samples with poor collagen scores. This proof of concept can be done since low Collagen score tumors have the same outcome than high Collagen score tumors, as illustrated above. Additionally the proportion of stages and events is maintained in this subanalysis. Kaplan-Meier survival plots after excluding samples below the $25^{\text {th }}$ percentile of the collagen score $(n=107$ patients). The 5-gene classifier identifies two risks groups. Five-year DFS and DSS (not shown) survival rates according to the 5-gene signature score improved significantly excluding very low stroma patients.

Post-test probabilities confirmed the clinical utility of the 5-gene classifier for clinical decision-making, most notably in Stage-II patients (Table 2).

\section{Physiological status rather than the quantity of CAFs confers prognostic value}

We hypothesized that the prognostic value of the 5-gene classifier reflects the physiological state of the CAFs rather than the number of fibroblasts in the tumor, and that samples with a very low percentage of CAFs might be misclassified since low levels of specific mRNAs would be present in the sample to be amplified among the large quantity of mRNA from other cell types. To test this, we obtained the most fibroblast-specific genes from GSE39396 (Supplementary figure 2A) and selected the two with the least variation in CAFs: COL1A1, and COL $3 A 1$. These genes were also associated specifically with CAFs from the breast [22]. We first demonstrated in vitro that there is a correlation between the number of fibroblasts in a sample and the expression of a collagen score (average expression of COL1A1, COL 3A1) independently of the type of fibroblasts used (Supplementary Figure 2B, top panels). On the other hand, there was no correlation with the five genes of the classifier (Supplementary Figure 2B, bottom panels). Thus, the 5-gene classifier reflects the physiological state of the CAFs rather than the number of fibroblasts in a sample, and different CAF phenotypes are probably present in the same tumor, demonstrating the heterogeneity of the CAFs (Supplementary Figure 2C). In applying this assumption to tumor samples, we found that the performance of the ROC curve analysis of the collagen score for recurrence prediction was negligible, as illustrated in Figure $3 \mathrm{G}(\mathrm{AUC}=0.48)$. Additionally, a high collagen score was not associated with recurrence $(\mathrm{P}=0.729)$ in our $\mathrm{PCR}$ cohort, in contrast to the 5-gene signature $(\mathrm{P}<0.0001)$. In GSE14333 and GSE33113, the collagen score was also not associated with recurrence $(\mathrm{P}=0.271$ and $\mathrm{P}=0.369$; there is an association for GSE17538). Regarding DFS time, the categorization of our cohort (PCR dataset) according to this collagen score (high and low categories, using the $3^{\text {rd }}$ tertile as a cut off) were not related to clinical outcome (log-rank test, $\mathrm{P}=0.938$; Figure $3 \mathrm{H} ; \mathrm{P}=0.785$ using the median collagen score as cut off) and the same results were obtained in GSE14333 ( $\mathrm{P}=0.525$, Supplementary figure 2D). Collagen score as a continuous variable was not associated with DFS (Cox regression analysis, $\mathrm{P}=0.904$ ). Thus, many high collagen samples were assigned as low-risk (Figure 3I). We also used immunohistochemical staining to evaluate PDLIM3 in high-stroma tumors quantified in H-E slides as the tumor/stroma ratio. As shown in Figure 3J, two high-stroma tumors, one classified as high-risk according to the 5-gene signature score, with intense $\alpha$-SMA and PDLIM3 staining, and the other classified as low-risk according to our gene classifier, with intense $\alpha$-SMA but without PDLIM3 positivity. Additionally hematoxylineosin evaluation of stroma percentage in these samples reported no statistically significant differences between high stroma and low stroma groups (Kaplan-Meier Log Rank P = 0.123; Supplementary figure 3A). Since neither the quantity of collagen nor the stroma percentage provided consistent results regarding patient's outcome, we confirmed by means a Kaplan-Meier analysis that the 5-gene classifier can help to stratify highly desmoplastic tumours according to recurrence risk. Accordingly, using 
the median Collagen score value as a cut off, in high collagen score samples, the 5-gene classifier clearly stratify patients according to risk $(\mathrm{HR}=14.47$, $\mathrm{P}=0.00036)$, while in low collagen score samples did not ( $\mathrm{HR}=1.56, \mathrm{P}=0.344)$. This association is also illustrated in supplementary figures $3 \mathrm{D}$-to-F stratifying patients in three groups according to Collagen score. The same trend is observed in dataset GSE17538 (supplementary figures $3 \mathrm{G}-$-to-I).

Additionally, we also investigate this fact in tumors regarding the tumor/stroma percentage assessed by hematoxylin-eosin staining. The 5-gene classifier also stratifies patients according to risk of relapse in the high stroma group (Supplementary figure 3J and K).

\section{Performance of the 5-gene classifier excluding very low-stroma samples}

We assumed, given the aforementioned results, that samples with a low collagen score might be misclassified due to the low level of CAFs in such specimens. To prove that, we excluded samples with collagen score $<$ percentile 25. After discarding these samples, as proof of concept, the cohort comprised 107 patients, with same stages proportionality. As demonstrated by the KaplanMeier curves (Figure $3 \mathrm{~K}$ and supplementary figure 3B and $\mathrm{C}$ ), the prognostic power of the 5-gene classifier is considerably superior. Therefore, as shown in Table 2, the assessment of the 5-gene classifier in samples relatively enriched in the stromal compartment differentiated patients into two risk groups. Actually, as illustrated in supplementary table 2 (ROC analysis), the predictive capability of the 5-gene classifier increases as we discard samples according to their collagen score. Thus a cohort containing samples with low collagen scores has a smaller AUC than a cohort enriched in samples containing higher collagen scores. The predictive power increases if Collagen is present, assuming that Collagen means fibroblasts. To corroborate this fact, we performed an interaction analysis between the collagen score and the 5-gene classifier (Supplementary table 3 ) to demonstrate that the classifier has better predictive capabilities in samples with a higher collagen score.

Thus, selecting the 107 samples with high collagen scores (above the $25^{\text {th }}$ percentile), the 5-gene classifier is still the strongest predictor of DFS in univariate and multivariate analyses (univariate: $\mathrm{HR}=6.87,95 \%$ $\mathrm{CI}=3.02-15.49, \mathrm{P}<0.0001$; multivariate: $\mathrm{HR}=6.18,95 \%$ $\mathrm{CI}=2.61$ - 14.6, $\mathrm{P}<0.0001$; Table 3). Using the 5-gene signature score as a continuous variable, the HR increased by $1.36(95 \% \mathrm{CI}=1.18-1.57, \mathrm{P}<0.0001)$ per unit increase in the SD of expression. The 5-gene signature was also significant in multivariate analysis when used as a continuous variable $(\mathrm{HR}=1.34,95 \% \mathrm{CI}=1.14-1.58$, $\mathrm{P}<0.0001$ ). In addition, post-test probabilities (Table 2) demonstrated the suitability of the 5-gene classifier for clinical practice.

\section{DISCUSSION}

In this paper, we report the development, validation and technique translation (RT-PCR) of a 5-gene classifier (including risk genes ULBP2, SLC7A2, PDLIM3, $A M I G O 2$, and the protective gene $C C L 11$ ) derived from a 108-gene expression signature obtained from a microarray of deregulated genes in CAFs from colorectal cancer (Molecular Oncology 10.1016/j.molonc.2014.04.006). The 5-gene classifier is associated with the risk of relapse in patients with Stage II and Stage III CRC, regardless of the number of fibroblasts in the tumor specimen.

Not all the cells in a tumor are transcriptionally equivalent, and this is the case for CAFs. This is a consequence of the spatial location of each cell within the tumoral microecosystem, arising first from the particular relationships with other cells and other cell types, and second from the anatomical demarcation of a tumor and the mechanical and compressive forces exerted by the surrounding tissue (tensegrity) $[23,24]$. Thus, recently, greater complexity has been revealed in the form of the considerable inter-tumoral heterogeneity of CAFs in the same organ as we and others have reported (Molecular Oncology 10.1016/j.molonc.2014.04.006) [25]. This suggests that the physiological status of CAFs may be more relevant in terms of the prognostic information provided than the number of fibroblasts itself. Therefore, a key concept in this study is that multiple, distinct biological responses are present to different extents within the CAFs of a given tumor, and the balance between these responses determines the good or bad prognostic value. Accordingly, our unsupervised analysis of the most variable genes in isolated CAFs clearly segregated two different patterns. The first comprises CAFs with the four overexpressed risk genes (AMIGO2, PDLIM3, ULBP2 and SLC7A2) and the underexpressed protective gene (CCL11). This subset is characterized by the overexpression of genes involved in the processes of migration, wound healing, angiogenesis, TGF $\beta$ responsive genes and downregulation of inflammatory genes. The second pattern involves a cluster enriched in inflammatory genes and the underexpression of the four risk genes. This is consistent with a previously observed stromal signature in breast cancer [26] in which samples from the good outcome cluster overexpressed a distinct set of immune-related genes. These good outcome tumors also have higher levels of fibroblasts expressing CXCL14, a chemokine that stimulates natural killer cell migration. Thus, individuals with this gene expression pattern may benefit from treatments targeting tumor cells via the immune response. In contrast, individuals with a poor outcome have higher levels of expression of stromal genes 
Table 2. Post test recurrence probabilities values for the clinical value of the 5-gene signature score in each validation dataset.

\begin{tabular}{|c|c|c|c|c|c|c|c|}
\hline & & Prevalence & LR+ & LR- & $\begin{array}{l}\text { Positive } \\
\text { post test } \\
\text { probability }\end{array}$ & $\begin{array}{l}\text { Negative } \\
\text { post test } \\
\text { probability }\end{array}$ & Difference \\
\hline \multirow{4}{*}{$\begin{array}{l}\text { In silico } \\
\text { Meta-cohort } \\
(\mathrm{n}=317)\end{array}$} & All stages & $0.325(0.27-0.38)$ & \begin{tabular}{|l|}
2.61 \\
$(1.88-3.6)$
\end{tabular} & $\begin{array}{l}0.59 \\
(0.48-0.73)\end{array}$ & $\begin{array}{l}0.56 \\
(0.45-0.65)\end{array}$ & $\begin{array}{l}0.22 \\
(0.17-0.28)\end{array}$ & 0.34 \\
\hline & Stage I & $0.11(0.02-0.28)$ & \begin{tabular}{|l}
2.08 \\
$(0.33-13.05)$ \\
\end{tabular} & $\begin{array}{l}0.79 \\
(0.35-1.79)\end{array}$ & $\begin{array}{l}0.2 \\
(0.01-0.7) \\
\end{array}$ & $\begin{array}{l}0.08 \\
(0.015-0.29)\end{array}$ & 0.12 \\
\hline & Stage II & $0.29(0.22-0.36)$ & \begin{tabular}{|l|}
.96 \\
$(1.92-4.56)$
\end{tabular} & \begin{tabular}{|l}
0.53 \\
$(0.38-0.73)$
\end{tabular} & $\begin{array}{l}0.55 \\
(0.41-0.68)\end{array}$ & $\begin{array}{l}0.18 \\
(0.12-0.26)\end{array}$ & 0.37 \\
\hline & Stage III & $0.43(0.34-0.53)$ & \begin{tabular}{|l|}
.09 \\
$(1.23-3.53)$
\end{tabular} & $\begin{array}{l}0.67 \\
(0.5-0.88)\end{array}$ & $\begin{array}{l}0.62 \\
(0.45-0.76)\end{array}$ & $\begin{array}{l}0.34 \\
(0.23-0.45) \\
\end{array}$ & 0.28 \\
\hline \multirow{3}{*}{$\begin{array}{l}\text { PCR validation } \\
\text { Initial cohort } \\
(n=142)\end{array}$} & All stages & $0.30(0.23-0.39)$ & \begin{tabular}{|l|}
2.52 \\
$(1.57-4.04)$
\end{tabular} & $\begin{array}{l}0.59 \\
(0.42-0.82)\end{array}$ & $\begin{array}{l}0.52 \\
(0.37-0.67)\end{array}$ & $\begin{array}{l}0.20 \\
(0.13-0.3)\end{array}$ & 0.32 \\
\hline & Stage II & $0.19(0.11-0.32)$ & $\begin{array}{l}3.65 \\
(1.64-8.07)\end{array}$ & $\begin{array}{l}0.50 \\
(0.25-0.97)\end{array}$ & $\begin{array}{l}0.47 \\
(0.22-0.73)\end{array}$ & $\begin{array}{l}0.11 \\
(0.04-0.24)\end{array}$ & 0.36 \\
\hline & Stage III & $0.39(0.28-0.5)$ & $\begin{array}{l}1.95 \\
(1.1-3.46)\end{array}$ & $\begin{array}{l}0.66 \\
(0.45-0.96)\end{array}$ & $\begin{array}{l}0.55 \\
(0.36-0.73)\end{array}$ & $\begin{array}{l}0.29 \\
(0.18-0.44)\end{array}$ & 0.26 \\
\hline \multirow{3}{*}{$\begin{array}{l}\text { PCR validation } \\
\text { Collagen score } \\
\text { Percentil25 } \\
(\mathrm{n}=107)\end{array}$} & All stages & $0.28(0.2-0.38)$ & $\begin{array}{l}3.53 \\
(2.17-5.74)\end{array}$ & $\begin{array}{l}0.34 \\
(0.18-0.61)\end{array}$ & $\begin{array}{l}0.58 \\
(0.41-0.73) \\
\end{array}$ & $\begin{array}{l}0.12 \\
(0.05-0.22)\end{array}$ & 0.46 \\
\hline & Stage II & $0.17(0.08-0.3)$ & \begin{tabular}{|l}
7.17 \\
$(3.02-17)$ \\
\end{tabular} & $\begin{array}{l}0.14 \\
(0.02-0.89)\end{array}$ & $\begin{array}{l}0.58 \\
(0.29-0.83) \\
\end{array}$ & $\begin{array}{l}0.02 \\
(0.001-0.16) \\
\end{array}$ & 0.56 \\
\hline & Stage III & $0.38(0.26-0.51)$ & \begin{tabular}{|l}
2.23 \\
$(1.26-3.94)$
\end{tabular} & \begin{tabular}{|l}
0.46 \\
$(0.24-0.86)$
\end{tabular} & $\begin{array}{l}0.58 \\
(0.35-0.75)\end{array}$ & $\begin{array}{l}0.22 \\
(0.1-0.4)\end{array}$ & 0.36 \\
\hline
\end{tabular}

To assess the potential usefulness of the 5-gene signature on clinical practice we evaluate the post test recurrence probabilities and we compared them to the a priori expected event proportion. For the in silico meta-cohort, considering all stages (expected recurrence value $32.5 \%$ ) the post-test recurrence probability for the high-risk group increased to $56 \%$ and for the low-risk group the prediction was $22 \%$ probability of recurrence (34\% absolute difference). Stratifying by stage, Stage I patients recurrence prevalence was $11 \%$, but the post test probabilities increases to $20 \%$ for high-risk patients and decreases to $8 \%$ for low-risk patients. The 5-gene classifier had more potential clinical value for stages II-III. The absolute difference between positive posttest probability and negative post-test probability was $37 \%$ for stage II and $28 \%$ for stage III patients. On the other hand, for PCR cohort, considering all stages (expected recurrence value 30\%) the probability of recurrence bearing a tumour with high expression of the 5-gene classifier increased to $52 \%$ and decreased to $20 \%$ in low expression tumours. In stage II the expected probability of relapse is $19 \%$. According to the 5-gene classifier, bearing a high expression tumour, this value increases to $47 \%$ and the value decreased to $11 \%$ in case of low-risk tumours. Thus, the absolute difference is $36 \%$.

From the PCR cohort, considering samples with Collagen score $>$ percentile25, the clinical value of the 5-gene classifier increases and is especially remarkable for stage II patients. As an example, selecting samples with Collagen score above percentile25 ( $\mathrm{n}=107)$, the a priori probability of relapse of a stage II patient is $17 \%$. Applying the 5 -gene classifier, the probability of relapse will increase to $58 \%$ in case of bearing a high expression tumour, and will decrease to only $2 \%$ in case of a low expression tumour.

involved in wound healing and angiogenesis. Several matrix metalloproteases are also strongly expressed.

The prognostic utility of stroma has recently been more widely reported although it is still not used routinely. Some authors have proposed using the percentage of tumor/stroma as a tool for classifying outcome in a variety of cancer types [27-30], even though these methods have some bias and do not take into account the intratumor heterogeneity with respect to transcriptomic status. In our cohort, the tumor stroma percentage did not associate with prognosis (Supplementary figure 3A), at least in the 106 cases available, although a trend is observed. Other authors evaluated the prognostic value of stroma or particular stromal cell types from the point of view of their transcriptional status [26, 31-33]. In relation to other CAF-specific genes our 5-gene classifier predicted 
Table 3. Univariate and multivariate analysis for DFS in quantitative RT-PCR validation dataset.

\begin{tabular}{|c|c|c|c|c|c|c|}
\hline & \multicolumn{3}{|c|}{ univariate } & \multicolumn{3}{|c|}{ multivariate } \\
\hline & P value & HR & $95,0 \% \mathrm{CI}$ & P value & HR & $95,0 \% \mathrm{CI}$ \\
\hline \multicolumn{7}{|l|}{ Initial cohort $(n=142)$} \\
\hline Gender (female vs male) & 0.07 & 0.55 & $0.29-1.04$ & & & \\
\hline Age $>55$ years & 0.88 & 0.93 & $0.37-2.36$ & & & \\
\hline Stage (3 vs 2 ) & 0.013 & 2.33 & $1.19-4.53$ & 0.084 & 1.91 & $0.92-3.97$ \\
\hline Location (rectum vs colon) & 0.055 & 1.79 & $0.99-3.26$ & & & \\
\hline Grade (high vs low) & 0.033 & 2.42 & $1.07-5.45$ & 0.52 & 1.33 & $0.56-3.16$ \\
\hline isolated nodes $(<14$ vs $>14)$ & 0.063 & 1.77 & $0.97-3.24$ & & & \\
\hline Lymphatic invasion (no) & 0.049 & 0.53 & $0.28-0.99$ & 0.37 & 0.73 & $0.37-1.45$ \\
\hline Adjuvant chemotherapy (no) & 0.083 & 1.71 & $0.93-3.14$ & & & \\
\hline Collagen score (high vs low) & 0.689 & 0.88 & $0.46-1.66$ & & & \\
\hline 5-gene classifier (high vs low) & $<0.0001$ & 3.14 & $1.72-5.72$ & 0.002 & 2.67 & $1.42-5$ \\
\hline 5-gene classifier (continuous, $+1 \mathrm{SD}$ ) & 0.005 & 1.19 & $1.05-1.34$ & $0.032 *$ & 1.16 & $1.01-1.32$ \\
\hline \multicolumn{7}{|l|}{ >percentil25 Collagen score $(n=107)$} \\
\hline Gender (female vs male) & 0.115 & 0.61 & $0.28-1.3$ & & & \\
\hline Age $>55$ years & 0.7 & 0.79 & $0.24-2.6$ & & & \\
\hline Stage (3 vs 2 ) & 0.014 & 2.76 & $1.23-6.21$ & 0.363 & 1.57 & $0.67-3.69$ \\
\hline Location (rectum vs colon) & 0.003 & 2.99 & $1.44-6.23$ & 0.009 & 2.76 & $1.3-5.9$ \\
\hline Grade (high vs low) & 0.023 & 2.82 & $1.15-6.93$ & 0.78 & 1.14 & $0.45-2.94$ \\
\hline isolated nodes $(<14$ vs $>14)$ & 0.067 & 1.95 & $0.95-4$ & & & \\
\hline Lymphatic invasion (no) & 0.052 & 0.48 & $0.23-1$ & & & \\
\hline Adjuvant chemotherapy (no) & 0.51 & 1.27 & $0.62-2.61$ & & & \\
\hline Collagen score (high vs low) & 0.361 & 0.71 & $0.34-1.47$ & & & \\
\hline 5-gene classifier (high vs low) & $<0.0001$ & 6.87 & $3.02-15.49$ & $<0.0001$ & 6.18 & $2.61-14.6$ \\
\hline 5-gene classifier (continuous, $+1 \mathrm{SD}$ ) & $<0.0001$ & 1.36 & $1.18-1.57$ & $<0.0001 *$ & 1.34 & 1.14-1.58 \\
\hline
\end{tabular}

"Multivariate analysis including Stage, location, grade and 5-gene signature score as a continuous variable.

recurrence with higher accuracy (Supplementary table 4). Interestingly, the 5 -gene classifier is able to discriminate the a priori bad outcome highly desmoplastic tumors into two groups of risk.

More recently, many of the new molecular classifications have considered the stromal contribution to prognosis [34-36] [37] [38]. We only found overlap between two genes of our classifier and a recent molecular classification [38]. We were not surprised at this since the small number of genes in our classifier and its origin is based on the transcriptional changes between NCF and paired CAFs. By contrast, we found considerable overlap with the signature derive from other CAFs signatures from breast, lung, oral squamous cell carcinoma and esophagus $[32,39-41]$.
Integrating all the available information, it can be concluded that the stroma plays an extremely important role in the prognosis of colorectal cancer. Our results emphasize that the quantity of CAFs in a tumor is not as important as their transcriptomic or physiological status. Our 5 -gene classifier, comprising genes almost exclusively expressed by CAFs, seems to reflect the physiological state of these myofibroblasts rather than just the number of fibroblasts in the tumor stroma. By contrast, the collagen score reflects the quantity of fibroblasts in a given sample and could be used to estimate the desmoplastic reaction. The lack of prognostic value of the collagen score with respect to the binary event (recurrence) and disease-free survival, leads us to suggest that the quantity of CAFs is not important for prognosis. With respect to the genes of 
the classifier, four are considered to be risk genes, since their level of expression is positively correlated with the risk score, and CCL11 is considered to be a protective gene, its value being negatively correlated with the risk score. This is consistent with the levels of expression in NCFs and CAFs used to develop the differential signature (Molecular Oncology 10.1016/j.molonc.2014.04.006). This can be explained in two ways. One possibility is that fibroblasts in a tumor have heterogeneous transcriptomic profiles, although all of them are considered as CAFs, which, depending on their interaction with their surroundings (i.e., crosstalk with other cells), express these genes in a particular manner, leading to distinct CAF subpopulations coexisting in a tumor. The net balance of gene expression, rather than the quantity of fibroblasts, is what ultimately determines the prognostic value. In other words, the positional demarcation of a fibroblast in a tumor determines the crosstalk with its surroundings, and this can therefore be measured in terms of mRNA transcription. Another explanation for such CAF heterogeneity is that there are different origins [42].

Remarkably, the 5-gene classifier identifies Stage-II patients at high risk of relapse independently of the $\mathrm{pT}$, and Stage-III patients at low risk of relapse. We found that the 5-year DFS rate was $>90 \%$ in Stage-II patients who had a low 5-gene classifier score. This rate could be extended to Stage-III patients when selecting an appropriate biopsy from the surgical specimen to perform the test. This suggests that adjuvant chemotherapy would be of minimal benefit to this group of patients, especially those classified as Stage-II. Some authors have reported that the association of stromal gene expression with colorectal recurrence may explain the AJCC staging in which invasion is the critical feature [43]. Our study suggests that there is no statistical association with disease stage. Multivariate Cox regression analysis confirmed that the classifier, either as a dichotomized or a continuous variable, is an independent prognostic factor in Stage II/ III colorectal cancer. Additionally, the way in which the classifier has been developed enhances the biological relevance of it component genes, since no regression coefficients were used to obtain the score, and the genes were weighted equally.

The performance of the 5-gene classifier in independent, whole tumor-derived data sets and with two distinct technologies (microarray and PCR) indicates that although the prognostic power of the classifier is specific to tumor stroma, the signal can be detected when a minimal amount of stromal tissue is present in the sample. Moreover, prediction accuracy increases along with the quantity of stromal tissue, although this is not associated with a higher risk of relapse, as indicated by the lack of prognostic value of the collagen score.

The use and benefit of adjuvant chemotherapy in Stage-II patients is controversial [4], but the QUASAR study suggested that a subset of Stage-II patients with higher relapse risk may benefit from adjuvant treatment. Stage-III patients are routinely offered adjuvant chemotherapy but, despite treatment, approximately $40 \%$ of them relapse [3]. Our 5-gene stromal classifier identifies subgroups with different recurrence risk even though there is a wider clinical margin between high-risk and low-risk patients in Stage-II compared with Stage-III patients.

\section{CONCLUSIONS}

In conclusion, using the 5-gene classifier in a clinical setting can provide more accurate information about the risk of recurrence than is possible from conventional clinicopathological criteria alone, and may facilitate the selection of high-risk Stage-II patients who would benefit from adjuvant therapy. Additionally, the predictive power of the 5-gene classifier is precise and accurate when selecting an area/biopsy from the surgical specimen that is relatively rich in tumor stroma (Figure $3 \mathrm{~K}$ ), as previously reported in prostate cancer [44]. The small number of genes comprising this classifier, and its validation in RT-PCR make it more amenable to clinical use than are large signatures. As is the case for other studies that have developed signatures, a limitation of this one is that it has only been possible to carry out a retrospective analysis of prospectively collected specimens. Future prospective studies are needed to confirm whether Stage-II patients at high-risk of relapse based on our classifier can achieve a better outcome if they receive adjuvant chemotherapy. Nonetheless the extensive in silico validation, and the translation and validation with PCR demonstrate the robustness of this 5-gene stromal classifier.

\section{METHODS}

\section{Training and validation series: patients.}

All public datasets were obtained from the GEO (Gene Expression Omnibus) and corresponded to the gene expression profile (GEP) of CRC patients obtained with the microarray platform (Affymetrix Human Genome U133Plus 2.0). GSE14333 was used as the training set. Datasets used for external validation corresponded to the GEP of whole tumor samples and GSE33113, GSE17538, and GSE14095. GSE31595 and GSE26892 were included in the meta-analysis. Datasets GSE18105 and GSE21510, containing GEP of LCM (laser capture microdissection) of epithelial cells from CRC patients, were used for negative validation of the stromal classifier. Table 1 illustrates the characteristics of the patients in the training set, the in silico validation metacohort and the RT-PCR validation cohort. 


\section{Specimen characteristics.}

Training and validation datasets obtained from GEO corresponded to whole tumor specimens. PCR validation dataset consisted in retrospective 142 frozen whole tumor samples stored at $-80^{\circ} \mathrm{C}$ and collected from the Hospital Universitari de Bellvitge Tumor Bank from 1996 until 2001.

\section{Classifier development}

Figure 1 depicts the process by which the classifier was developed. The 5-gene classifier is derived from a 108-gene signature of differentially expressed genes (DEGs) between carcinoma-associated fibroblasts (CAFs) and paired normal colonic fibroblasts (NCFs) (Molecular Oncology 10.1016/j.molonc.2014.04.006).

\section{In silico validation}

The optimal predictive classifier was validated in three independent datasets (GSE17538, GSE14095 and GSE33113). GSE14333 and GSE17538 cohorts were partially overlapping. Cases duplicated in GSE14333 and GSE17538 were excluded from validation. We also performed a meta-analysis, pooling GSE26892 and GSE31595 with the aforementioned GSE17538 and GSE33113 datasets (metacohort $\mathrm{n}=317$; Table 1). In order to remove systematic biases between datasets, the expression levels of all genes were transformed to z-scores before pooling. A recurrence score was computed for each sample (see the Supplementary Methods).

\section{Gene expression analysis by $q R T-P C R$ in validation-PCR dataset}

Frozen primary tumor tissue samples $(\mathrm{n}=142)$ from colorectal cancer patients (62 Stage-II, 80 Stage-III) were collected from the Hospital Universitari de Bellvitge Tumor Bank. Clinical and pathological data of these patients were obtained from the medicals records and reviewed for the study. RNA isolation and real-time PCR procedures are detailed in the Supplementary Methods.

\section{RNA isolation and real time PCR procedures.}

RNA was extracted from whole tumor tissue (both stroma and epithelial compartment) using TRIzol ${ }^{\circledR}$ reagent method and column purification using PureLink TM RNA Mini Kit (Invitrogen). RNA quantity was determined by NanoDrop ND-1000 spectrophotometer (NanoDrop Technologies Inc, Rockland, DE) and 100ng of total RNA was reverse-transcribed using M-MLV Reverse Transcriptase (Invitrogen) following manufacturer's instructions. A $0.1 \mu \mathrm{g}$ equivalent of the corresponding cDNA was used for each quantitative PCR assay performed with the LightCycler ${ }^{\circledR}$ 480, SYBR Green I Master (Roche Applied Science, Mannheim, Germany). Primers were designed using Primer3 Input (http://primer3 .wi.mit.edu) and predicted PCR product sequences were verified by using BLAST (http://www.ncbi.nlm.nih.gov/ blast). All primer sequences will be provided upon request. In every qRT-PCR reaction, a standard curve made from serial dilutions of a mix of RNA from different isolated fibroblasts was added to extrapolate for cDNA amount of the specific gene. To control for variation in RNA quantity between samples, the expression of each gene was further normalized to the geometric mean of two specifically selected reference genes. We aimed to use a reference gene in common at least between NCF, CAF and colorectal cell lines, attempting to prevent that the ratio tumor/ stroma affected the normalization of the classifier genes. Different possible housekeeping genes (ACTB, PMM1, GAPDH, B2M, HPRT1, PPIA, IPO8, RSP13) were tested for stability in 10 colon cancer tissue samples as well as in different colorectal cancer cell lines and in a mix of RNA from NCF and CAF and in mixes of NCF, CAF and CRC cell lines. Using RefFinder, a web-base tool (http://leonxie .com/referencegene.php) which integrates different online applications (Normfinder [45], geNorm [46], BestKeeper [47] and $\Delta C t$ [48]), candidate reference genes mentioned above, were compared and ranked to select those with more stability. ACTB and PMMI were the most stable genes between all different samples tested. Normalized values were further $\log$ transformed and standardized.

\section{Recurrence score estimation}

A recurrence score for a given patient was calculated as the sum of the standardized value of each gene. No gene level parameter estimation was performed and coefficients were established as 1 for overexpressed genes in CAF vs. NCF (PDLIM3, SLC7A2, ULBP2 and $A M I G O 2$; risk genes) and -1 for underexpressed gene in CAF vs. NCF (CCL11, protective gene). Patients in each cohort were classified according to their 5-gene expression score as having a high-risk gene signature or a low-risk gene signature. As a cut off we used the $3^{\text {rd }}$ tertile of the classifier score (percentile 66.66) in the training set. Then low-risk patients were define as those with score $<1.1328$ and high-risk patients as those above 1.1328. The same cut off value was applied to all other validation cohorts

\section{Statistical analysis}

Kaplan-Meier survival analyses with the log-rank test were used to estimate five-year disease-free survival (DFS) and disease-specific survival (DSS) rates in the different cohorts tested. DFS and DSS were defined as the time until an event (relapse, locoregional or metastasis, and death from $\mathrm{CRC}$, respectively), and patients were 
censored at last follow-up, cancer-related death or treatment-related death. In all datasets, a minimum threeyear follow-up was required for patients without tumor recurrence. More detailed information is provided in supplementary statistical methods.

\section{Conflict of Interests}

The is no conflict of interest of any form.

\section{ACKNOWNLEDGEMENTS}

This work is supported by grants of the Spanish Government PI07/0657 and P10/1604.

\section{REFERENCES}

1. Ferlay J, Shin HR, Bray F, Forman D, Mathers C and Parkin DM. Estimates of worldwide burden of cancer in 2008: GLOBOCAN 2008. Int J Cancer. 127(12): 2893-2917.

2. O'Connell JB, Maggard MA and Ko CY. Colon cancer survival rates with the new American Joint Committee on Cancer sixth edition staging. J Natl Cancer Inst. 2004; 96(19):1420-1425.

3. Andre $\mathrm{T}$, Boni C, Mounedji-Boudiaf L, Navarro M, Tabernero J, Hickish T, Topham C, Zaninelli M, Clingan P, Bridgewater J, Tabah-Fisch I and de Gramont A. Oxaliplatin, fluorouracil, and leucovorin as adjuvant treatment for colon cancer. The New England journal of medicine. 2004; 350(23):2343-2351.

4. Gray R, Barnwell J, McConkey C, Hills RK, Williams NS and Kerr DJ. Adjuvant chemotherapy versus observation in patients with colorectal cancer: a randomised study. Lancet. 2007; 370(9604):2020-2029.

5. Ragnhammar P, Hafstrom L, Nygren P and Glimelius B. A systematic overview of chemotherapy effects in colorectal cancer. Acta oncologica (Stockholm, Sweden). 2001; 40(2-3):282-308.

6. Van Schaeybroeck S, Allen WL, Turkington RC and Johnston PG. Implementing prognostic and predictive biomarkers in CRC clinical trials. Nature reviews. 2011; 8(4): 222-232.

7. van de Vijver MJ, He YD, van't Veer LJ, Dai H, Hart AA, Voskuil DW, Schreiber GJ, Peterse JL, Roberts C, Marton MJ, Parrish M, Atsma D, Witteveen A, Glas A, Delahaye L, van der Velde T and et al. A geneexpression signature as a predictor of survival in breast cancer. The New England journal of medicine. 2002; 347(25):1999-2009.

8. Sun Z, Wigle DA and Yang P. Non-overlapping and noncell-type-specific gene expression signatures predict lung cancer survival. J Clin Oncol. 2008; 26(6):877-883.
9. Beer DG, Kardia SL, Huang CC, Giordano TJ, Levin AM, Misek DE, Lin L, Chen G, Gharib TG, Thomas DG, Lizyness ML, Kuick R, Hayasaka S, Taylor JM, Iannettoni MD, Orringer MB and et al. Gene-expression profiles predict survival of patients with lung adenocarcinoma. Nature medicine. 2002; 8(8):816-824.

10. Glinsky GV, Glinskii AB, Stephenson AJ, Hoffman RM and Gerald WL. Gene expression profiling predicts clinical outcome of prostate cancer. The Journal of clinical investigation. 2004; 113(6):913-923.

11. Sanz-Pamplona R, Berenguer A, Cordero D, Riccadonna S, Sole X, Crous-Bou M, Guino E, Sanjuan X, Biondo S, Soriano A, Jurman G, Capella G, Furlanello C and Moreno V. Clinical value of prognosis gene expression signatures in colorectal cancer: a systematic review. PloS one. 2012; 7(11):e48877.

12. Webber EM, Lin JS and Evelyn PW. Oncotype DX tumor gene expression profiling in stage II colon cancer. Application: prognostic, risk prediction. PLoS Curr. 2. 2010

13. Tan IB and Tan P. Genetics: an 18-gene signature (ColoPrint(R)) for colon cancer prognosis. Nat Rev Clin Oncol. 2011, 8(3):131-133.

14. Salazar R, Roepman P, Capella G, Moreno V, Simon I, Dreezen C, Lopez-Doriga A, Santos C, Marijnen C, Westerga J, Bruin S, Kerr D, Kuppen P, van de Velde C, Morreau H, Van Velthuysen L and et al. Gene expression signature to improve prognosis prediction of stage II and III colorectal cancer. J Clin Oncol. 2011; 29(1):17-24.

15. Comprehensive molecular characterization of human colon and rectal cancer. Nature. 2012; 487(7407):330-337.

16. Sadanandam A, Lyssiotis CA, Homicsko K, Collisson EA, Gibb WJ, Wullschleger S, Ostos LC, Lannon WA, Grotzinger C, Del Rio M, Lhermitte B, Olshen AB, Wiedenmann B, Cantley LC, Gray JW and Hanahan D. A colorectal cancer classification system that associates cellular phenotype and responses to therapy. Nature medicine. 2013 ; 19(5):619-625.

17. De Sousa EMF, Vermeulen L, Fessler E and Medema JP. Cancer heterogeneity-a multifaceted view. EMBO reports. 2013; 14(8):686-695.

18. Wang X, Markowetz F, De Sousa EMF, Medema JP and Vermeulen L. Dissecting cancer heterogeneity - An unsupervised classification approach. The international journal of biochemistry \& cell biology. 2013; 45(11):2574-2579.

19. Calon A, Espinet E, Palomo-Ponce S, Tauriello DV, Iglesias M, Cespedes MV, Sevillano M, Nadal C, Jung P, Zhang XH, Byrom D, Riera A, Rossell D, Mangues R, Massague J, Sancho E and et al. Dependency of colorectal cancer on a TGF-beta-driven program in stromal cells for metastasis initiation. Cancer Cell. 2012; 22(5): 571-584.

20. De Wever O and Mareel M. Role of tissue stroma in cancer cell invasion. J Pathol. 2003; 200(4):429-447. 
21. Meads MB, Gatenby RA and Dalton WS. Environmentmediated drug resistance: a major contributor to minimal residual disease. Nat Rev Cancer. 2009; 9(9):665-674.

22. Perou CM, Sorlie T, Eisen MB, van de Rijn M, Jeffrey SS, Rees CA, Pollack JR, Ross DT, Johnsen H, Akslen LA, Fluge O, Pergamenschikov A, Williams C, Zhu SX, Lonning PE, Borresen-Dale $\mathrm{AL}$ and et al. Molecular portraits of human breast tumours. Nature. 2000; 406(6797):747-752.

23. Noguera R, Nieto OA, Tadeo I, Farinas F and Alvaro T. Extracellular matrix, biotensegrity and tumor microenvironment. An update and overview. Histology and histopathology. 2012; 27(6):693-705.

24. Ingber DE. Cancer as a disease of epithelial-mesenchymal interactions and extracellular matrix regulation. Differentiation; research in biological diversity. 2002; 70(9-10)547-560.

25. Herrera M, Islam AB, Herrera A, Martin P, Garcia V, Silva J, Garcia JM, Salas C, Casal I, de Herreros AG, Bonilla F and Pena C. Functional heterogeneity of cancerassociated fibroblasts from human colon tumors shows specific prognostic gene expression signature. Clin Cancer Res. 2013; 19(21):5914-5926.

26. Finak G, Bertos N, Pepin F, Sadekova S, Souleimanova M, Zhao H, Chen H, Omeroglu G, Meterissian S, Omeroglu A, Hallett $M$ and Park M. Stromal gene expression predicts clinical outcome in breast cancer. Nature medicine. 2008; 14(5):518-527.

27. de Kruijf EM, van Nes JG, van de Velde CJ, Putter H, Smit VT, Liefers GJ, Kuppen PJ, Tollenaar RA and Mesker WE. Tumor-stroma ratio in the primary tumor is a prognostic factor in early breast cancer patients, especially in triple-negative carcinoma patients. Breast cancer research and treatment. 2011; 125(3):687-696.

28. Dekker TJ, van de Velde CJ, van Pelt GW, Kroep JR, Julien JP, Smit VT, Tollenaar RA and Mesker WE. Prognostic significance of the tumor-stroma ratio: validation study in node-negative premenopausal breast cancer patients from the EORTC perioperative chemotherapy (POP) trial (10854). Breast cancer research and treatment. 2013; 139(2):371-379.

29. Huijbers A, Tollenaar RA, v Pelt GW, Zeestraten EC, Dutton S, McConkey CC, Domingo E, Smit VT, Midgley R, Warren BF, Johnstone EC, Kerr DJ and Mesker WE. The proportion of tumor-stroma as a strong prognosticator for stage II and III colon cancer patients: validation in the VICTOR trial. Ann Oncol. 2013; 24(1):179-185.

30. Tsujino T, Seshimo I, Yamamoto H, Ngan CY, Ezumi K, Takemasa I, Ikeda M, Sekimoto M, Matsuura N and Monden M. Stromal myofibroblasts predict disease recurrence for colorectal cancer. Clin Cancer Res. 2007; 13(7): 2082-2090.

31. Chang HY, Sneddon JB, Alizadeh AA, Sood R, West RB, Montgomery K, Chi JT, van de Rijn M, Botstein D and
Brown PO. Gene expression signature of fibroblast serum response predicts human cancer progression: similarities between tumors and wounds. PLoS biology. 2004; 2(2):E7.

32. Navab R, Strumpf D, Bandarchi B, Zhu CQ, Pintilie M, Ramnarine VR, Ibrahimov E, Radulovich N, Leung L, Barczyk M, Panchal D, To C, Yun JJ, Der S, Shepherd FA, Jurisica I and et al. Prognostic gene-expression signature of carcinoma-associated fibroblasts in non-small cell lung cancer. Proceedings of the National Academy of Sciences of the United States of America. 2011; 108(17):7160-7165.

33. Gao Q, Wang XY, Qiu SJ, Zhou J, Shi YH, Zhang BH and Fan J. Tumor stroma reaction-related gene signature predicts clinical outcome in human hepatocellular carcinoma. Cancer science. 2011; 102(8):1522-1531.

34. Perez-Villamil B, Romera-Lopez A, Hernandez-Prieto S, Lopez-Campos G, Calles A, Lopez-Asenjo JA, SanzOrtega J, Fernandez-Perez C, Sastre J, Alfonso R, Caldes T, Martin-Sanchez F and Diaz-Rubio E. Colon cancer molecular subtypes identified by expression profiling and associated to stroma, mucinous type and different clinical behavior. BMC cancer. 2012; 12:260.

35. Marisa L, de Reynies A, Duval A, Selves J, Gaub MP, Vescovo L, Etienne-Grimaldi MC, Schiappa R, Guenot D, Ayadi M, Kirzin S, Chazal M, Flejou JF, Benchimol D, Berger A and Lagarde A. Gene expression classification of colon cancer into molecular subtypes: characterization, validation, and prognostic value. PLoS medicine. 2013; 10(5):e1001453.

36. Budinska E, Popovici V, Tejpar S, D'Ario G, Lapique N, Sikora KO, Di Narzo AF, Yan P, Hodgson JG, Weinrich S, Bosman F, Roth A and Delorenzi M. Gene expression patterns unveil a new level of molecular heterogeneity in colorectal cancer. J Pathol. 2013; 231(1):63-76.

37. Roepman P, Schlicker A, Tabernero J, Majewski I, Tian S, Moreno V, Snel MH, Chresta CM, Rosenberg R, Nitsche U, Macarulla T, Capella G, Salazar R, Orphanides G, Wessels LF, Bernards R and et al. Colorectal cancer intrinsic subtypes predict chemotherapy benefit, deficient mismatch repair and epithelial-to-mesenchymal transition. Int J Cancer. 2014; 134(3):552-562.

38. De Sousa EMF, Wang X, Jansen M, Fessler E, Trinh A, de Rooij LP, de Jong JH, de Boer OJ, van Leersum R, Bijlsma MF, Rodermond $\mathrm{H}$, van der Heijden $\mathrm{M}$, van Noesel CJ, Tuynman JB, Dekker E, Markowetz F and et al. Poor-prognosis colon cancer is defined by a molecularly distinct subtype and develops from serrated precursor lesions. Nature medicine. 2013; 19(5):614-618.

39. Bauer M, Su G, Casper C, He R, Rehrauer W and Friedl A. Heterogeneity of gene expression in stromal fibroblasts of human breast carcinomas and normal breast. Oncogene. 2010; 29(12):1732-1740.

40. Lim KP, Cirillo N, Hassona Y, Wei W, Thurlow JK, Cheong SC, Pitiyage G, Parkinson EK and Prime SS. Fibroblast gene expression profile reflects the stage of 
tumour progression in oral squamous cell carcinoma. J Pathol. 2011; 223(4):459-469.

41. Zhang C, Fu L, Fu J, Hu L, Yang H, Rong TH, Li Y, Liu H, Fu SB, Zeng YX and Guan XY. Fibroblast growth factor receptor 2-positive fibroblasts provide a suitable microenvironment for tumor development and progression in esophageal carcinoma. Clin Cancer Res. 2009; 15(12):4017-4027.

42. Worthley DL, Giraud AS and Wang TC. Stromal fibroblasts in digestive cancer. Cancer Microenviron. 2010; 3(1): 117-125.

43. O’Connell MJ, Lavery I, Yothers G, Paik S, Clark-Langone KM, Lopatin M, Watson D, Baehner FL, Shak S, Baker J, Cowens JW and Wolmark N. Relationship between tumor gene expression and recurrence in four independent studies of patients with stage II/III colon cancer treated with surgery alone or surgery plus adjuvant fluorouracil plus leucovorin. J Clin Oncol. 2010; 28(25):3937-3944.

44. Jia Z, Rahmatpanah FB, Chen X, Lernhardt W, Wang Y, Xia XQ, Sawyers A, Sutton M, McClelland M and Mercola D. Expression changes in the stroma of prostate cancer predict subsequent relapse. PloS one. 2012; 7(8):e41371.
45. Andersen CL, Jensen JL and Orntoft TF. Normalization of real-time quantitative reverse transcription-PCR data: a model-based variance estimation approach to identify genes suited for normalization, applied to bladder and colon cancer data sets. Cancer research. 2004; 64(15): 5245-5250.

46. Vandesompele J, De Preter K, Pattyn F, Poppe B, Van Roy N, De Paepe A and Speleman F. Accurate normalization of real-time quantitative RT-PCR data by geometric averaging of multiple internal control genes. Genome biology. 2002; 3(7):RESEARCH0034.

47. Pfaffl MW, Tichopad A, Prgomet $\mathrm{C}$ and Neuvians TP. Determination of stable housekeeping genes, differentially regulated target genes and sample integrity: BestKeeper-Excel-based tool using pair-wise correlations. Biotechnology letters. 2004; 26(6):509-515.

48. Silver N, Best S, Jiang J and Thein SL. Selection of housekeeping genes for gene expression studies in human reticulocytes using real-time PCR. BMC molecular biology. 2006; 7:33. 